\title{
WHY *JOHN CAN'T CONTRIBUTE MARY MONEY. CONSTRUCTIONAL BEHAVIOR OF CONTRIBUTE VERBS ${ }^{77}$
}

\author{
Andreea Rosca, University of Valencia \\ Francisco J. Ruiz de Mendoza, University of La Rioja \\ Email: andreea.rosca@uv.es, francisco.ruizdemendoza@unirioja.es
}

\begin{abstract}
This article examines the conceptual structure of the main constructions in which Levin's (1993) contribute verbs appear, viz. the ditransitive and the dative constructions, which often alternate. The present paper questions the reliability of Levin's semantic criterion for contribute verbs and shows that the integration of these verbs into the dative construction is licensed by several factors, such as the presence of multiple agents, multiple transferred entities and multiple recipients which deprofile the possessive relationship between a unique recipient and an object (e.g. contribute, administer, distribute), and the conceptual prominence of the motion event over the possession relationship between the recipient and the object (e.g. refer, transfer), among others.

Keywords: ditransitive construction, dative construction, Lexical Constructional Model, internal/external constraints, Focal Prominence Compatibility constraint.
\end{abstract}

Resumen: Este artículo examina la estructura conceptual de las principales construcciones en las que aparecen los verbos de contribución de Levin (1993), concretamente las construcciones ditransitiva y dativa que alternan a menudo. El presente trabajo cuestiona la fiabilidad del criterio semántico de Levin para los verbos de contribución y demuestra que la subsunción de estos verbos en la construcción dativa se rige por varios factores, como la presencia de múltiples agentes, múltiples entidades transferidas y múltiples recipientes que desenfocan la relación de posesión entre un único recipiente y un objeto (ej. contribuir, administrar, distribuir), y la prominencia conceptual del evento de movimiento sobre la relación de posesión entre el recipiente y el objeto (ej. remitir, transferir), entre otros.

Palabras clave: construcción ditransitiva, construcción dativa, Modelo Léxico Construccional, restricciones internas y externas, Compatibilidad de la Prominencia Focal.

\section{INTRODUCTION}

The main concern of this study is to explain the cognitive principles that regulate the constructional use of Levin's (1993) contribute verb class. Levin (1993: 138) includes contribute verbs within the larger class of verbs of change of possession. According to

77 The research on which this paper is based has been financed by the Spanish Ministry of Economy and Competitiveness, grant no. FFI2013-43593-P. 
this author, contribute verbs differ from other sister classes (e.g. verbs of giving, future having, and get verbs) in that they cannot participate in the ditransitive construction (cf. *We contributed her our paycheck, but We gaveloffered/got her a job), but they take part in the dative construction (e.g. We contributed our paycheck to her), which we will treat (see section 3 below) as a subcase of the caused-motion construction. Nevertheless, our corpora examples clearly demonstrate that some of these verbs do accept the ditransitive construction (section 4). Furthermore, there are very few linguists (e.g. Davidse 1996; Van der Leek 1996) that have been concerned with the analysis of this verbal class in connection to the dative construction. This is striking in the light of the fact that contribute verbs, as will be shown below, have an idiosyncratic constructional behavior which separates them off from other verb classes. It will also be argued that an exclusively lexicalist approach like the one propounded by Levin (1993) is not the key to the (in)compatibility of these verbs with the ditransitive and the dative constructions.

The theoretical framework of our analysis is the Lexical Constructional Model or LCM (Ruiz de Mendoza and Mairal 2008; Ruiz de Mendoza 2013). This model stands halfway between Goldberg's (2006) top-down account and the bottom-up constructionist approaches propounded by authors like Boas (2003), Iwata (2008), or Nemoto (2005). The LCM boasts an explanatory apparatus of internal and external constraints which constitute useful analytical tools to account for the constructional behavior of contribute verbs. The internal constraints concern the internal structure of a predicate, i.e. its encyclopedic and event structure makeup whereas the external constraints refer to construal mechanisms such as high-level metaphor and metonymy.

This article is organized as follows. In section 2 we devote some space to the aspects of the LCM that have proved useful to endow our study with explanatory adequacy. In section 3 we introduce the reader to the ditransitive and the dative constructions, which are our object of study. Section 4 critically reviews Levin's (1993) semantic criterion for contribute verbs whereas sections 4.1,4.2, and 4.3 discuss the factors that motivate their lexical-constructional behavior. The final section summarizes all the findings of our investigation.

\section{WHY THE LEXICAL CONSTRUCTIONAL MODEL?}

We have chosen the LCM as a theoretical framework for our study since Goldberg's (2006) broad generalizations, while elegant, have proved by themselves insufficient to fully help us to discern why some verbs combine more easily with a given construction while others do not. In the same vein as Langacker (1991: 331), Goldberg distinguishes between the participant roles of a verb and the argument roles of a construction. In her view, participant roles of verbs "fuse" with the argument roles of constructions, which can contribute roles not present in the lexical predicate characterizations. There are two principles that regulate this fusion process (Goldberg 2005: 8): (i) The Semantic Coherence Principle, which posits that that there must be semantic compatibility between the participant and argument roles, and (ii) The Correspondence Principle, by which the participant roles that are semantically salient must fuse with grammatical relations that provide them with discourse prominence.

It is true that in some cases constructions constitute better meaning predictors than verbs. Thus, the transfer meaning of the sentence John kicked Tom the ball is clearly supplied by 
the ditransitive construction, which augments the quantitative valence of the predicate kick. However, Goldberg's constructionist approach falls short of providing a full explanation of lexical-constructional integration in several respects. First, her explanatory apparatus places excessive emphasis on the role performed by constructions, while the rich semantic information supplied by verbs is neglected. For the sake of clarity, take into account the intransitive resultative construction [...] an army mutiny rapidly ballooned into a major political rebellion [...] (Sketch engine doc\#1151065). It may be true that the result is supplied by the construction itself but the choice of this result is greatly constrained by the information encapsulated into the metaphorical use of the verb balloon (i.e. the intensity of the mutiny, which may end up in a major outbreak of violence, is seen in terms of a balloon swelling to a point in which it may burst out) and by the changing entity. Therefore, the $\mathrm{Z}$ element (political rebellion) has greater meaning implications than the Y element (mutiny). In the LCM this phenomenon is explained by means of the constraint labeled Internal Variable Conditioning, which regulates the way in which the conceptual structure from verbal predicates places constraints on the nature of constructional arguments.

Boas (2003: 113-116; 2008b: 120-123) has argued that Goldberg's broad-scale lexical entries fail to predict the distributional pattern within a specific verbal class. For example in our case, the verbs donate and contribute share the same minimal set of participant roles (cf. donate <donor donation donee>, contribute <contributor contribution goal/ contributee $>$ ), but only the former is allowed to fuse with the ditransitive construction (e.g. She donated him her kidney; *She contributed the collection 1000\$). From this we can infer that lexical entries are not sufficient to explain the difference between these two verbs at the syntactic level. Therefore, the best solution to this problem is to find a model that gives more prominence to lower-level configurations and the lexical information associated with them. A coherent lexical-constructional model is the one propounded by Boas (2003). Nevertheless, Boas's focus on mini-constructions is excessive, to the detriment of high-level constructions, their argument structure contribution and the possible principles that regulate the interaction between verbs and constructions. Mini-constructions are form-meaning pairings differing in complexity from more abstract constructions. Consider the AHTY mini-construction or ' a hole through the $\mathrm{Y}$ '. There are two main verb classes that combine with this construction: Class I, which comprises verbs such as push, knock, burn, and blow (e.g. He suggests we knock a hole through the wall), and Class II, which contains verbs like drill, create, make, and dig (e.g. Using a hammer drill and carbide bit, drill a hole through the sill plate). The AHTY construction describes an activity carried out by an agent applying energy, where the activity causes the creation of a hole in a surface. Obviously the definition of this mini-construction rules out figurative uses of AHTY (e.g. Claire glared/stared a hole through Natasha). We wonder if we must posit a new mini-construction for this additional meaning. Boas (2008a: $25 \mathrm{ft} 10$ ) admits that his analysis ignores metaphorical uses of this mini-construction simply because they display low productivity. However, we contend that such statement should at least be endorsed by a frequency based search of these verbs. Luzondo (2011: 84) points out that the LCM explains these figurative usages by means of the high-level metaphor AN ACTIVITY IS AN 
EFFECTUAL ACTION,${ }^{78}$ which enables us to conceive the staring look of a person as if it were able to physically affect a patient. A similar explanation holds true for the sentence [...] emails blew a hole through Mr. McNulty's testimony (Sketch engine doc\#201938), in which a testimony that is dismantled by further evidence is understood in terms of an object whose physical integrity has been altered.

The LCM only postulates constructions (at whatever level of granularity, including mini-constructions) when no other higher-level explanatory mechanism is capable of dealing with a specific form-meaning association. Among its analytical tools we find the following (cf. Ruiz de Mendoza 2013; Ruiz de Mendoza and Galera 2014 for more detailed accounts):

1. Vertical constraints: these include across-level conceptual compatibility constraints at whatever degree of abstraction. The Internal Variable Compatibility constraint deals with the encyclopedic-knowledge structure of lexical items. This is low-level conceptual structure. For example, we know that horses bray and cats purr. The sentence When will your cat stop braying?, while not impossible, is odd on account of our world knowledge. The solution to this conceptual compatibility problem lies in finding contextual reasons where the sentence is possible with special meaning effects (for example, the cat makes a strange noise that sounds like a horse's bray and bothers the speaker). On a higher level, the different event structure of the otherwise related verbs demolish and break endows them with likewise different constructional realization possibilities. Thus, the verb break can occur in the transitive, resultative, and inchoative constructions: The child broke the vase (into a thousand little fragments); The vase broke. By contrast, the verb demolish can only be integrated into the first two constructions: They demolished the building (into rubble); but it cannot have an inchoative use: *The building demolished. The reason for the different constructional behavior between break and demolish, despite lower-level semantic similarities, is to be found in corresponding differences in their event-structure (or high-level) characterization: break involves a change of state, while demolish is a cessation-of-existence verb, i.e. they belong to different lexical classes at their highest level of meaning-structure characterization. This is just one among other possible Lexical Class constraints identified in the LCM (cf. Galera and Ruiz de Mendoza 2012; Rosca 2012).

Another vertical constraint is the Event Identification Condition. According to it, for a verb to be subsumed into a construction, both must have the same event structure. This means, for example, that only caused motion verbs can take part in the caused-motion construction, as is the case of kick,push, and hit: They kicked/ pushed/hit the ball into the hole. This constraint can be overridden in several ways. An interesting possibility is provided by metaphorical re-construal, as in My boss stared me out of her office. In this example, the verb stare, which is only a target-oriented activity verb, is re-construed as if it were an effectual action predicate (like caused-motion predicates). In this way, psychological impact giving

78 The term activity makes reference to a goal-oriented activity, i.e. one where there is a target. 
rise to self-instigated motion is seen as if it were physical impact causing external motion. This re-construal has syntactic consequences: the (conative) preposition $a t$, which is used to introduce the target of the staring activity, is dropped and the object is syntactically treated as a common object in a transitive configuration; the construction adds an extra argument (realized as a motion prepositional phrase) to the original configuration for stare.

The last constraint that we will treat in this subsection is the Focal Compatibility Constraint, which places limitations on the constructional behavior of verbal predicates on the basis of conceptual prominence factors. For example, whereas the verb send can be used, in the context of information transmission, both with the dative and the ditransitive constructions (He sent the message to me and He sent me the message), the verb fax is better used in the dative construction (i.e. He faxed the message to the company is preferred to He faxed the company the message). This is due to the fact that the verb fax means 'to send a fax to communicate a message', thus giving prominence to the communicative activity (and the role of the fax machine in it) but not to the transfer of information, which means that the message is not profiled as a possession. Since the ditransitive, but not the dative construction focuses on the possession of the transferred element, it follows that the ditransitive use of fax creates a focal prominence clash.

2. Horizontal constraints. There are two related horizontal constraints: PredicateArgument Conditioning and Internal Variable Conditioning. The former requires co-instantiation consistency both between a predicate and its arguments and among all the arguments. For example, She drove me into despair is licensed by this constraint, but not *She drove her car into despair. The co-instantiation of the predicate 'drive' and the prepositional phrase in the figurative-motion construction call for a human object. This is not the case if we have a different prepositional phrase calling for a non-figurative use of the caused-motion construction (She drove the car into the pond). The latter constraint is based on the encyclopedic knowledge requirements of a verbal predicate when used in a given construction. For example, think of the use of the verb shrink in the figurative motion construction: The number of scientologists has shrunk into half in recent years. Since 'shrinking' involves a decrease in size, which carries over metaphorically to amount, it would be impossible to use the same configuration as follows: *The number of scientologists has shrunk into twice as many in recent years.

3. External constraints, especially (high-level) metaphor and metonymy. These involve re-construing the event-structure of a predicate in such a way that it can be made to fit into a constructional configuration with different event-structure requirements. The metaphorical re-construal of stare discussed above provides a clear example. Another example is supplied by inchoative constructions. These are possible when an action predicate can be seen as if it were a process that is then made to stand for the underlying action. In The door opened we know that there is an animate entity or a force that has performed the action of opening the 
door. However, the speaker has chosen to re-construe the action as if it were not such but a process where the true agent can be seen as instrumental. The resulting expression stands for the underlying action: The door opened with/*by the wind, i.e. the wind opened the door.

\section{THE DITRANSITIVE AND THE DATIVE CONSTRUCTIONS}

Before focusing on the principles that license or block out the participation of contribute verbs in the dative alternation, we would like to provide readers with a brief overview of this constructional phenomenon. The dative alternation (also termed 'dative shift') is made up of 'internal' versus 'external' dative (Wierzbicka 1988) or a dative realized by double objects [NP/SUBJ [VP/PRED NP/OBJ1 NP/OBJ2]] (e.g. John gave Susan a book) versus a dative realized by a prepositional phrase, either to or for [NP/SUBJ [VP/PRED NP/OBJ PP/OBL]] (e.g. John gave a book to Susan). The former receives the name of ditransitive construction whereas the latter is called dative construction. From now on, the term construction will replace the notion of syntactic alternation, which is reminiscent of Chomskyan derivations. The LCM treats this notion as epiphenomenal, viz. the side effect of variation in lexical-constructional subsumption (cf. Ruiz de Mendoza and Mairal 2011). In the transformational tradition, the ditransitive construction was understood as a derivation from the dative or prepositional construction, while in the LCM, like in cognitively-oriented constructionist accounts of language, the two constructions arise independently of each other, but can be used as alternate ways of construing the same state of affairs. For example, I gave the book to John (dative) looks at the giving action in terms of the spatial transfer of an object from the giver to the receiver (i.e. the gift moves), while I gave John the book (ditransitive) focuses on the end-result of the action (the book is in John's possession).

Furthermore, the dative and ditransitive constructions do not always alternate. Goldberg (1995) has accounted for the conditions that may block the use of the ditransitive. Goldberg (1995) states that the ditransitive construction can be skeletally represented as X CAUSES Y TO RECEIVE Z. This construction is regulated by the following semantic constraints:

(i) It supplies transfer semantics that cannot be ascribed to the lexical verb.

(ii) The goal argument must be animate (recipient rather than patient).

(iii) Two non-predicative NPs are licensed in post-verbal position.

(iv) The recipient role is correlated with an object function.

(v) The subject position must be occupied by a volitional agent who intends transfer.

Thus, in the sentence Sue knitted Mary a sweater, the transfer meaning is contributed by the ditransitive construction and not by the lexical verb knit, which solely describes the creation of a fabric or garment by joining thread in a series of connected loops, either by hand, using knitting needles or on a machine. The semantic constraint in (ii) was postulated to account for the ungrammaticality of utterances like *John sent Madrid the book, where Madrid, which is not a prototypical recipient but an inanimate location, cannot be said to actively participate in the reception event. Goldberg herself (1992: 61) remarks that the recipient animacy constraint is obscured by an example like The music lent the party a 
festive air, where neither the subject nor the receiver are animate. She solves this problem by postulating the CAUSAL EVENTS ARE TRANSFERS metaphor which allows the animacy of the recipient to be satisfied in the source domain, but not the target domain of the metaphor.

Furthermore, the semantic constraint in (v) blocks out the subsumption of verbs like pony up, cough up, shell out, or fork out into the ditransitive construction (cf. George ponied up/ coughed up/shelled out/forked out \$3000 to Bob vs. *George ponied up/coughed up/shelled out/forked out Bob \$3000). The LCM accounts for these cases by means of the Lexical Class constraint whereby membership to a certain verbal class determines the syntactic behavior of that verb. Thus, the verbs mentioned above belong to a class that gathers all the verbs encoding unwillingness of transfer on the part of the agent. The agent's unwillingness to transfer an entity to the recipient makes these verbs incompatible with the ditransitive construction, which requires the agent's intention to cause the recipient to have an entity.

At this point, it is worth noting that the semantic constraint in (v) does not seem to hold for the following: [...] if he sometimes almost won, that lent him hope and kept him playing on (BNC 898) ${ }^{79}$. Nevertheless, Goldberg (1992) accounts for examples like this by postulating the low-level metaphor CAUSAL EVENTS ARE TRANSFERS. In our sentence the giver is mapped onto the causing entity, which is an event, whereas the receiver is projected onto the developer of hope. The effect of the event (i.e. producing hope) is viewed as the transfer of an object from a lender to a receiver. Holding possession of an object correlates in the target domain with the effects of the action of causing someone to be hopeful. Goldberg (1992: 61) also argues that volitionality is not mapped onto the target domain simply because the target domain refers to abstract causes and volition is a human trait. No explanation is given for the ungrammaticality of the dative counterparts (e.g. *that lent hope to him). Panther (1997) takes up this issue and claims that the concept of causation in these cases is too abstract to be conceptualized in terms of a moving object sent by an agent along a path to a receiver. However, this argument is less than convincing given that it is possible to treat as objects very abstract concepts such as love (He has a lot of love for mankind), hate (We could see hate in his eyes), ideas (The idea came across fine), beliefs (The beliefs she has are to be respected), and so on. Besides, Panther does not give any criteria to determine whether a concept is more abstract than others. Thus, a better solution to the problem comes from the field of conceptual prominence. The verb lend in this expression is used in the sense of 'provide support which is not to be returned.' As mentioned above, the ditransitive construction gives prominence to the possession relationship between the receiver and the object, in contrast to the dative construction, whose focus of attention is on the transfer process. It follows that the ditransitive construction is a better choice to capture the 'provide support' meaning of this use of lend.

One last note should be made here about the ditransitive construction. According to Panther (1997), the syntactic position of the indirect object in the ditransitive construction iconically reflects the strong impact of the verb onto the recipient and it strengthens the

79 Our examples have been extracted from the British National Corpus (BNC), The Corpus of Contemporary American English (COCA), and The Sketch Engine. Unlike the BNC and the COCA, which are instances of monolingual corpora, the Sketch engine provides access to large corpora (ranging from 30 million to 10 billion words) for 42 languages. 
implicature of possession, which is cancellable in the case of the prepositional construction (cf. I handed my book to him, but he didn't take it vs. ? I handed him my book, but he didn't take it).

As far as the dative construction is concerned, the LCM treats it, like Goldberg (1995, 2002), as a subcase of the caused-motion construction (X CAUSES Y TO MOVE Z, where the $\mathrm{Z}$ element denotes the path of motion expressed by the oblique or directional prepositional phrase). The dative construction can be explained in terms of give verbs being licensed into the caused-motion construction by the high-level metaphor TRANSFER IS MOTION. Take for example the sentences in (1):

(1) a. John gave a book to Mary.

b. John sent a book to Mary.

c. John sent a book to Madrid.

Sentence (1a) illustrates a prototypical dative construction since the transfer-of-possession meaning conveyed by the verb give, although construed in terms of motion of the gift to its destination, still prevails over the motion element and the destination of motion is primarily construed as a human recipient. Example (1b) is a less prototypical case of the dative construction since it explicitly incorporates the motion element through the verb send; the human recipient is thus primarily construed as the destination of motion. Finally, (1c) is a canonical case of the caused-motion construction since it combines a motion verb with an inanimate location as the destination of motion; the existence of a potential human recipient is to be inferred. The examples reproduced in (1)(a)-(c) reveal that there is a continuum from a pure transfer meaning (1a) to a purely motional meaning (1c). The dative construction (1a) is only a subcase of the caused-motion construction where the dative element does not arise from the construction itself but from the combination of a transfer verb and a human recipient. When dealing with the ditransitive and the dative constructions, Pinker (1989) posits that the ditransitive has the form [X acts-on Z] to the effect that [Z has $\mathrm{Y}$ ] whereas the prepositional variant [i.e. the dative] has the semantics [X acts-on Y] to the effect that [Y goes to Z]. As mentioned above, Goldberg $(1995,2002)$ considers the dative construction to be a daughter construction of the caused-motion construction (cf. Colleman and De Clerck 2009). Other scholars that have understood the dative construction as a case of caused motion are Pesetsky (1995), Panther (1997), Harley (2002) and Krifka (2004). Additionally, Pinker (1989) and Langacker (1991) understand the difference between the ditransitive and the dative in terms of focal prominence. In their view, the ditransitive construction focalizes the possessive relationship between a recipient and an entity whereas the dative construction stresses a path scenario, i.e. the trajectory followed by the transferred object. Similarly, Panther (1997) claims that the dative construction has a spatial (metaphorical) basis, that is to say, a spatial scenario involving motion is mapped onto a more abstract transfer-of-possession scenario. 


\section{LEVIN'S SEMANTIC CRITERION FOR CONTRIBUTE VERBS}

Levin (1993) lists eighteen verbs which share the conceptual structure and the syntactic configuration of the verb contribute, i.e. administer, disburse, distribute, donate, extend, forfeit, proffer, refer, reimburse, relinquish, remit, restore, return, sacrifice, submit, surrender, transfer. Levin (1993) claims that the internal semantic parameters of a verb function as important predictors of its range of syntactic representations. Thus, Levin's (1993: 138) contribute verbs must have in common a contribution sense which motivates their compatibility with the dative but not with the ditransitive (nor with the with-construction attested with entrust). Nevertheless, verbs like remit, return, reimburse, proffer, and even donate were found to participate in the ditransitive construction: ${ }^{80}$

(2) a. She was deprived of all means of remitting him money (Sketch engine doc\#1223079)

b. I returned him the keys [...] (Sketch engine doc\#220759)

c. The landowner reimbursed him $\$ 500$ of the cost of the fertilizer in February 2007 (Sketch engine doc\#1118556)

d. He smilingly proffered me a cup of watered wine [...] (COCA 1992)

e. Luckily for him his cousin donated him a kidney (Sketch engine doc\#299426)

These counterexamples cast doubt on the validity of Levin's (1993) semantic criterion for verbs of contribution. Can we really say that a verb inherits its syntactic behavior exclusively from one semantic class? And what is more, what should we understand by a contribution sense? The presence of several donors with their several donations, the benefactive meaning supplied by the action performed by the agent/agents or both? What most of these verbs have in common is the fact that the action denoted by the verb is somewhat beneficial for the recipient. Thus, in the sentence He had previously relinquished his post to his brother [...] (BNC GSX 534) there is only one giver who renounces his position in favor of a recipient. In some cases it may happen that the transferred entity is not benefiting the receiver in any way. This can be observed in the sentence You mean, could I have administered poison to Sir Thomas? (COCA 1992), which lends itself to a malefactive reading, i.e. the recipient's life is threatened by an ingested entity. From this discussion still arises another question. Can we really assume that the use of the to-dative in this sentence is licensed by a contribution meaning? There is no collaboration of multiple agents nor does the sentential meaning involve a beneficial transfer for the recipient. Last, how would Levin account for a sentence like [...] he transferred it [the envelope] to the inside pocket of his jacket [...] (COCA 1979) ${ }^{81}$, in which there is only one agent, there is no animate recipient and the connotations of the transfer are neutral? If Levin grouped these verbs under

80 It should be mentioned that Levin (1993) classifies these five verbs as contribute verbs but she provides no examples to support their similarity in constructional behavior, i.e. participation in the dative construction and rejection of the ditransitive construction.

81 This sentence is similar to He restored the handkerchief to his pocket (BNC FS8 3840), in which another supposedly contribute verb is used in the dative construction. In this utterance a volitional agent moves a concrete entity to a location with the implication that that was the former location of the entity. 
the contribute class label because of the activation of a benefiter model, then what would differentiate this class from give-type verbs which can also involve a beneficial transfer for the recipient? So, how valid is this semantic criterion for the motivation of the dative construction? Obviously, in view of these problems, it is not a fully reliable one.

In the next sections the aim is to show that the subsumption of these verbs into the dative construction is licensed by several factors, such as (i) the presence of multiple agents, multiple transferred entities and multiple recipients that deprofile the possessive relationship between a unique recipient and an object; (ii) the lack of an animate recipient that can cooperate in the transferring event; (iii) the CONTAINER image-schema evoked by some verbs, and (iv) the motion to a different location that gains more prominence than the possession relationship between a recipient and an object. Hence, we cannot place the whole burden of subsumption uniquely on the conceptual make-up of verbs since lexical-constructional integration can also be governed by the focal requirements of a construction, by the semantics of the subject and objects, and by contextual factors, as generally postulated by the LCM.

\subsection{Multiple giving events}

After the above preamble on the principles that regulate the subsumption of Levin's (1993) contribute verbs into the dative construction, we move on to discuss them in greater detail.

We will first examine the case of the verb contribute. Consider the sentence We contributed our paycheck to her, which was extracted from Levin (1993: 139). This sentence is an example of the dative construction, which we treat as a subcase of the caused-motion construction, as already mentioned in section 3. The reason for this treatment lies in the experiential grounding of the meaning of the dative construction, which basically conveys a transfer of possession. However, the dative highlights the importance of the object transferred over the transfer itself (which in some cases may not even take place physically). As noted in Ruiz de Mendoza and Mairal (2011), a prototypical transfer of possession involves the giver handing the object over to the recipient. In this process, the giver loses possession of the object, which after the transfer has been completed, falls within the recipient's sphere of control. In this prototypical scenario, the giver is a causer of motion, the gift is a moving object and the recipient is the destination of motion. Non-prototypical uses of the dative construction substitute 'affording access to the object' for 'causing the object to move from the giver to the recipient' and 'gaining control' for 'gaining possession' of the object given. In We contributed our paycheck to her, which is an example of non-prototypical use, the paycheck is thus seen as coming under the control of the recipient, whether the paycheck has been physically and personally handed over to the recipient by the contributors or not. The dative construction is thus a special case of the caused-motion construction where there is a conflation between the roles of destination and recipient of an object, with greater degree of prominence on the recipient role.

As noted above, the dative construction can alternate with the ditransitive construction (cf. John gave a book to Peter/John gave Peter a book), each alternate involving a different case of construal. But the exceptions to this kind of alternation are notable. A case in point is the verb contribute, which cannot take part in the ditransitive construction (cf. *We con- 
tributed her our paycheck). The reason for this puzzling property of this verb, however, is not captured by the set of internal and external constraints postulated thus far in the LCM. Let us first consider internal constraints, which relate to the event structure of lexical items and their associated encyclopedic knowledge components. Contribute inherits much of its internal structure from give: there is a transfer of possession (any object for give and usually money for contribute) from a donor to a recipient. If the transfer involves a material object, there is also motion of the transferred object across space. Since we have both the possession and the transfer elements, it is only natural to find a transfer verb like give both in the ditransitive and the dative constructions. However, contribute, which contains the same transfer and possession elements as give, only takes part in the dative construction. If internal constraints based on the conceptual structure of the lexical and constructional configurations cannot account for this behavior, we may wonder whether this may be a matter of external constraints or not. However, upon closer scrutiny, this does not seem to be the case, since this verb is allowed in the dative construction on the same grounds as other give verbs and it is disallowed where no conversion process is required. Therefore, the solution to this problem needs to be found elsewhere. We would like to argue that the explanation is to be found in the area of focal prominence phenomena, as discussed in the context of Cognitive Grammar (cf. Langacker 1987, 1999). By way of illustration, consider Langacker's (1991: 13-14) explanation of the contrast between the dative and ditransitive in terms of the prominence given to certain facets of a 'sending' scenario. This explanation is consistent with the position taken by Goldberg (1995) but places more emphasis on focal prominence:

\section{(3) a. Bill sent a walrus to Joyce. b. Bill sent Joyce a walrus.}

The dative construction in ( $3 a$ ) lends more conceptual prominence to the trajectory followed by the transferred entity whereas ( $3 b$ ) focuses more on the possessive relationship between the walrus and Joyce which "results when the walrus completes its trajectory" (Langacker, 1991: 13-14). The difference between these two ways of construing the same event is supported by the acceptability of I sent a walrus to Antarctica and the ungrammaticality of ? I sent Antarctica a walrus. The first sentence is "fully acceptable because to emphasizes the path traversed by the walrus, and a continent can perfectly well be construed as the endpoint of a path" (1991: 14). The second sentence is incorrect because "it is harder to construe a continent as a possessor exercising control over other entities" (1991: 14).

However, the subsumption of the verb contribute into the dative construction cannot be explained only in terms of the destination-beneficiary perspective. This situation calls for the addition of another internal constraint to the list provided by the LCM. We shall call this constraint Focal Prominence Compatibility. According to this constraint, which is not based on structural compatibility between concepts, a verb cannot be fused with a construction if the inherent focal prominence requirements of the verb and the construction are different. Thus, the verb contribute means to "give something [money/goods/effort/ time/ideas/help] along with others to a common fund or for a common purpose". The basic schema of contribute is represented below: 


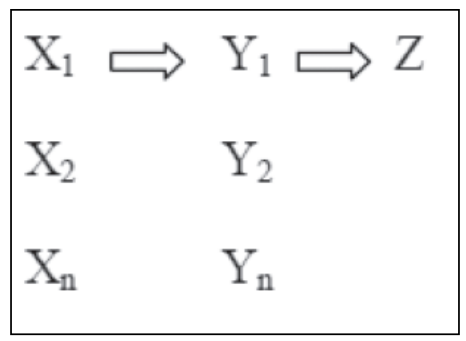

Figure 1. Basic schema of the verb contribute

$\mathrm{X}$ is the agent who causes $\mathrm{Y}$ (the amount of money) to go to $\mathrm{Z}$ (a common fund). The subscripted numbers (from 1 to $n$ ) refer to multiple subjects who give different amounts of money.

As can be observed, this verb presupposes the existence of multiple giving events, which makes it clash with the focal requirements of the ditransitive construction (i.e. a unique/single possessive relationship between a recipient and an object). ${ }^{82}$

Now, both contribute and donate exploit the motion construal in which entity Y moves from X to Z. Van der Leek (1996: 331) assumes that donate cannot appear in the ditransitive construction because the goal of this verb is typically an (inanimate) institution that cannot cooperate and the ditransitive construction requires cooperation on the part of the recipient (cf. *He threw the tree the ball). However, there are two problems with this assumption. First, an institution can in fact cooperate; it does so through the people who are responsible for it. Second, we find both ditransitive and dative uses of donate, as in Luckily for him his cousin donated him a kidney (Sketch engine doc\#299426) and [...] his cousin donated a kidney to him, where the recipient is animate and in fact does cooperate. What actually differentiates donate from other contribute-type verbs is that the object given (usually money) is intended for a good cause, i.e. there is an initial recipient, which may or may not be an institution, and a final beneficiary -which may or may not coincide with the recipient- which is generally recognized to be the best possible destination of the money. The difference between contribute and donate is that donations are not joint ventures, i.e. they are not made in common with others. That is why one "donates" (not contributes) blood or an organ. But donations, like contributions, involve the existence of a fund or an (expectedly beneficial) cause.

We now turn to another verb, distribute, which is defined as sharing things among the members of a particular group. Van der Leek (1996: 331) suggests that the reason why contribute and distribute only select the dative construction is that contribute presupposes

82 The verb contribute favors not only the dative construction but also other syntactic configurations which encode directionality and highlight the trajectory followed by a transferred entity (e.g. It is a tremendous achievement for the twenty-nine people of the department who all contributed towards the donation; BNC HRY 256; Kids contributed towards cleaning the house). These constructions are licensed by the metaphor GOALS ARE DESTINATIONS, whereby life purposes are conceptualized as destinations (cf. Tom and Mary are heading towards divorce). 
the existence of multiple givers and distribute implies the existence of multiple recipients. Thus, when someone contributes to a cause, it is taken for granted that there are other potential contributors. When distributing, there are many different receivers. The criterion required by the ditransitive construction, i.e. the complementariness between the roles of subject and first object (a.k.a. the indirect object), is not met since there is a multiple aspect linked to the subject role (contribute) and to the first object role (distribute). The latter verb can be envisaged as a reiterative giving event in which the same acting entity performs multiple movements to different locations in order to give an item of equal value to a number of people individually. Thus, in The cughtagh [...] distributed gifts to the needy folk in hill villages (COCA 1990), the individuality of the recipients is not important and their identity can be unknown, except for the sole information we have about them, viz. they are poor people living in hill villages. Therefore, the verb focalizes the action that enables the multiple recipients to come into the possession of the transferred entity. The Focal Prominence Compatibility constraint disallows the verb distribute from combining with a ditransitive construction since there are multiple recipients and it is difficult to focus on the possession relationship, which becomes secondary. Thus, the verb distribute displays the following basic schema:

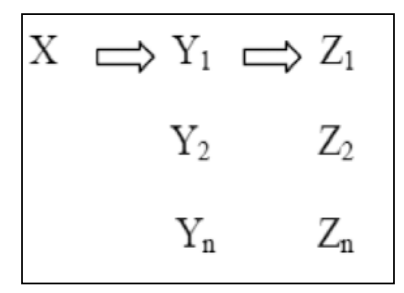

Figure 2. Basic schema of the verb distribute

Contribute is characterized by an expansion of the left wing of the basic schema whereas distribute, which is the mirror image of contribute, expands its right part (i.e. one distributer $\mathrm{X}$ gives multiple entities $\left(\mathrm{Y}_{1-\mathrm{n}}\right)$ to multiple recipients $\left.\left(\mathrm{Z}_{1-\mathrm{n}}\right)\right)$.

The verb administer can take a prepositional phrase headed by the preposition to (cf. One-third also administered medicines to clients [...]; COCA 1993) and it typically has the meaning of giving someone a measured amount of medication, often by physically introducing the medicine into that person's body, which evokes the image-schema of a transferred entity (medicine) moving from a container (hypodermic needle or syringe) into another container (a person's body). The verb administer favors the transfer perspective over the possession one as can be seen in the examples The tall woman struggled and continued to call out, until Britta stood back and administered a stinging slap to her face (COCA 1993), The lifeboat crew administered first-aid to the fisherman [...] (COCA 1993). We also contend that the specificity of the transferred entity (usually medicine) can be held responsible for the rejection of the ditransitive construction (cf. *The nurse administered the boy tranquillizers vs. *The nurse force-fed the patient the medicine). The ditransitive 
construction would imply that the patient behaves like a willing recipient, which is not the case here. The verb administer, which means "to give [a drug/medicine/treatment] to someone in small portions/doses", complies with the following basic schema:

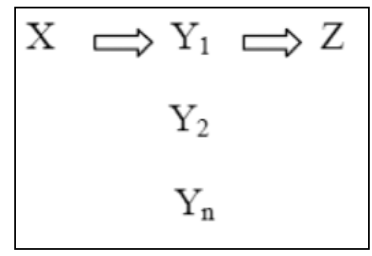

Figure 3. Basic schema of the verb administer

This development of the Y element incorporates an iterative component (i.e. portions of medicine are given at certain time intervals). This makes this verb incompatible with the ditransitive construction, which is focused on the receiver's possession of whatever is transferred rather than on the specificities of the process.

\subsection{Prominence of the motion construal}

A second major factor that explains the integration of some contribute verbs into the dative rather than the ditransitive construction relates to the fact that the motion to a different location is more conspicuous than the possession relationship between a recipient and an object (e.g. refer, reimburse, remit, restore, return, submit, extend, transfer). Consider the case of the verb refer which can only appear with a prepositional phrase headed by the preposition to, e.g. [...] my doctor referred me to a psychiatrist (BNC K53 40). The verb refer cannot possibly accept a ditransitive construction, as evidenced by the ungrammaticality of $* M y$ doctor referred a psychiatrist me, since no actual possession is entailed between the speaker and the specialist; the only thing that is implied by this verb is that someone is made to move to a different location or is transferred by his/her doctor to another doctor's office and this can only be conveyed by means of a dative as a subcase of the caused-motion construction.

Furthermore, we do not understand why Levin (1993) lists the verb transfer under the contribute class label given the fact that a transfer is not necessarily beneficial. In a sentence like [...] officers were transferring him to the county jail (Sketch engine doc\#24517) it is obvious that the location to which the direct object is moved has no positive connotations. Also, as has been discussed in section 4, the verb transfer can indicate a simple change of position of an entity from one location to another with no connotations attached to it as in [...] he transferred it [the envelope] to the inside pocket of his jacket [...](COCA 1979). So, can we really motivate the dative use of transfer by postulating a unique contribution sense (cf. In this case, we will transfer the money to you [...]; Sketch engine doc\#823584)? We consider that in the case of the verb transfer the motional meaning becomes conceptually more prominent than the possession relationship which sometimes is inexistent, i.e. there 
is no possessive relationship between a jail and its prisoners or between a pocket and its content. It is this shift in conceptual focalization that licenses the dative use of transfer and not its contributive sense.

\subsection{Miscellanea}

The presence of contribute verbs, such as disburse, forfeit, relinquish, sacrifice, and surrender, in the dative rather than the ditransitive construction, can be licensed by a number of factors that will be briefly discussed in what follows.

The image-schemas that certain verbs evoke (e.g. motion out of a container) make them suitable for the dative construction as in The government has already disbursed a large amount of money to the private sector. The verb disburse, which comes from the old French word desbourser "remove from the purse" (<bourse "purse"), suggests motion from a source to a destination, which explains the choice of the dative construction (cf. *The government has already disbursed the private sector a large amount of money).

The verbs forfeit, relinquish, sacrifice and surrender will be dealt with together since they are conceptually similar and can be grouped under the give up verbal class. The difference between the 'giving' act and the 'giving up' act lies in the fact that the former is understood as a voluntary transfer of information or property to another entity without receiving anything in return, whereas the latter is typically conceived either as a voluntary or involuntary act whereby a person leaves behind or stops doing a regular activity or abandons a habit without any transfer being involved. A sentence like $A$ good health scare helps people to give up smoking (Sketch engine doc\#748220) stresses the fact that the giving up event is caused by an external force (poor health) other than people's will. A dative construction construing a situation in which an agent renounces a habit in favor of another person would be impossible (cf. *He gave up smoking to her). It is quite difficult to imagine a context in which someone gives somebody else a habit since the giving act is a telic event (cf. ? John gave Mary the book for three hours) and starting a habit takes more time (cf. Years of working late at night gave me the habit of sleeping at the computer). However, the giving up event can also refer to cases in which somebody stops having or owning something in favor of someone else (e.g. [...] the seller will not be obligated to give up the item to the winner bidder [...]; Sketch engine doc\#55556).

The participation of forfeit, relinquish, sacrifice, and surrender in the dative construction $^{83}$ can be explained by means of the Internal Variable Conditioning constraint: world knowledge information encapsulated by the internal variables of these predicates requires the realization of what is given up as their immediate direct object (cf. *He sacrificed Juno the animal, where Juno would automatically be interpreted as the direct object and not the indirect object).

In addition, the sentence He sacrificed the animal to Juno is based on a high-level metaphor whereby communication is expressed in terms of motion. The act of killing an

83 Some corpus examples are provided here: [...] the Sandinistas forfeited power to Violeta Chamorro [...] (COCA 1992); He had previously relinquished his post to his brother [...] (BNC GSX 534); He sacrificed the animal to Juno (Sketch engine doc\#1136328); [...] Mithridates' generals in the city gave up all hope and surrendered the city to him [...] (Sketch engine doc\#174196). 
animal metonymically stands for the plea that the killer sends to the goddess in an attempt to appease her. This combination of metaphor and metonymy is schematically represented in Table I below:

\begin{tabular}{|l|l|}
\hline \multicolumn{1}{|c|}{ SOURCE } & \multicolumn{1}{c|}{ TARGET } \\
\hline Causer of motion & Speaker/sender \\
\hline Object of caused-motion (moving object) & Message of submission/obedience \\
\hline Causing motion & Communicating \\
& Animal sacrifice \\
\hline $\begin{array}{l}\text { Destination of motion (receiver of the } \\
\text { moving object) }\end{array}$ & Addressee \\
\hline
\end{tabular}

Table I. He sacrificed the animal to Juno

This sentence does not encode a spatial transfer of possession since the animal does not literally move from the killer to the goddess. It is rather a figurative type of transfer whereby a message of submission is conveyed to the goddess. The transmission of the message is understood as motion of a concrete object through space from the killer to the goddess.

\section{CONCLUSIONS}

According to Levin (1993), the internal semantic parameters of a verb can serve as predictors of its distributional patterns. However, we have demonstrated that Levin's semantic criterion for contribute verbs may not be entirely reliable and the integration of these verbs into the dative construction can be motivated by several factors, among which we will highlight the following:

(i) The Focal Prominence Compatibility constraint explains why the verb contribute cannot appear in the ditransitive construction. The inherent focal prominence requirements of this verb (i.e. the existence of multiple contributors with multiple contributions) clash with those of the ditransitive constructions (i.e. a single giving act).

(ii) The lack of complementariness between the roles of subject (agent) and first object (recipient) or, in Langacker's (1991) terms, the deprofiling of the possession relationship (e.g. The young woman distributed candies to all the children in her yard). The constructional choice for contribute verbs may also be due to the fact that with some of these verbs the individuality of the recipients may be irrelevant. Note that the recipient can be left out in distribute verbs but this is not a clear 
possibility in the case of give predicates: The girl distributed the leaflets [to the spectators] (cf. \#The girl gave the leaflets).

(iii) The motion construal can sometimes become more conspicuous than the possession relationship between a recipient and an object (e.g. My GP referred me to a specialist).

(iv) In some cases what is given up or back by the agent must be obligatorily lexicalized as an immediate direct object (e.g. He relinquished his post to his brother).

Our study has additionally provided evidence in favor of an account of verbal-constructional integration regulated by principles like those postulated within the LCM. Constructional features by themselves are not enough to explain how lexical structure can be fruitfully projected through them into actual linguistic realization; nor can lexical structure be conceded a purely subsidiary role. A balanced account needs to make explicit the cognitive mechanisms that either license or block the use of lexical predicates with a given construction. Such mechanisms, which act as constraints on lexical-constructional integration (called subsumption in the LCM), are based on conceptual compatibility at different levels of abstraction, on the possibility to re-construe event structure and on conceptual prominence phenomena.

\section{REFERENCES}

BOAS, H. 2000. Resultative constructions in English and German. Unpublished Doctoral dissertation, University of North Carolina.

2002. "On the role of semantic constraints in resultative constructions". Ed. R. RAPP. Linguistics on the way into the new millennium, 1. Frankfurt am Main: Peter Lang. 35-44.

2003. A constructional approach to resultatives. Stanford: CSLI Publications.

2008a. "Resolving Form-Meaning Discrepancies in Construction Grammar".

Ed. J. LEINO. Constructional reorganization. Amsterdam/Philadelphia: John Benjamins. 11-36.

2008b. "Determining the structure of lexical entries and grammatical constructions in Construction Grammar". Annual Review of Cognitive Linguistics 6. 113-144.

COLLEMAN, T. and B. DE CLERCK. 2009. “'Caused Motion?' The semantics of the English to-dative and the Dutch aan-dative". Cognitive Linguistics 20. 5-42.

DAVIDSE, K. 1996. "Functional dimensions of the dative in English". Eds. W. VAN BELLE and W. VAN LANGENDONCK. The Dative. Volume 1: Descriptive Studies. Amsterdam: John Benjamins. 289-338.

GALERA, A. and F. J. RUIZ DE MENDOZA. 2012. "Lexical class and perspectivization constraints on subsumption in the Lexical Constructional Model: The case of say verbs in English". Language Sciences 34. 54-64. 
GOLDBERG,A. 1992. "The inherent semantics of argument structure: The case of the English ditransitive construction”. Cognitive Linguistics 3, 1: 37-74.

1995. Constructions: A Construction Grammar approach to argument structure. Chicago: University of Chicago Press.

2002. "Surface generalizations: An alternative to alternations". Cognitive Linguistics 13, 4: 327-356.

2005. "Constructions, Lexical Semantics and the Correspondence Principle: Accounting for Generalizations and Subregularities in the Realization of Arguments". Eds. N. ERTESCHIK-SHIR and T. RAPOPORT. The Syntax of Aspect. Oxford: Oxford University Press. 215-254.

2006. Constructions at work: the nature of generalization in language. New York: Oxford University Press.

HARLEY, H. 2002. "Possession and the double object construction". Yearbook of Linguistic Variation 2, 29-68.

IWATA, S. 2008. The Locative Alternation: A lexical-constructional approach. Amsterdam/Philadelphia: John Benjamins.

KRIFKA, M. 2004. "Semantic and pragmatic conditions for the Dative Alternation". Korean Journal of English Language and Linguistics 4, 1-32.

LANGACKER, R. 1987. Foundations of Cognitive Grammar, Vol. 1: Theoretical prerequisites. Stanford: Stanford University Press.

1991. Foundations of Cognitive Grammar, Vol. 2: Descriptive Application. Stanford: Stanford University Press.

1999. Grammar and Conceptualization. Berlin/New York: Mouton de Gruyter.

LEVIN, B. 1993. English Verb Classes and Alternations. A Preliminary Investigation. Chicago/London: University of Chicago Press.

LUZONDO, A. 2011. English resultative constructions in the Lexical Constructional Model: implications for constructional modelling within a lexical conceptual knowledge base. Unpublished Doctoral dissertation, University of La Rioja.

MAIRAL, R. and F. J. RUIZ DE MENDOZA. 2008. "New challenges for lexical representation within the Lexical-Constructional Model”. Revista Canaria de Estudios Ingleses 57, 137-158.

2009. "Levels of description and explanation in meaning construction". Eds. C. S. BUTLER and J. MARTÍN ARISTA. Deconstructing Constructions. Amsterdam/ Philadelphia: John Benjamins. 153-198.

NEMOTO, N. 2005. "Verbal Polysemy and Frame Semantics in Construction Grammar: Some observations on the locative alternation". Eds. M. FRIED and H. C. BOAS. Grammatical Constructions - Back to the Roots. Amsterdam/Philadelphia: John Benjamins. 119-136. 
PANTHER, K.-U. 1997. "Dative Alternation from a cognitive perspective". Eds. B. SMIEJA and M. TASCH. Human Contact through Language and Linguistics. Frankfurt am Main: Lang. 107-126.

PESETSKY, D. 1995. Zero Syntax. Cambridge, MA: MIT Press.

PINKER, S. 1989. Learnability and Cognition. The Acquisition of Argument Structure. Cambridge, MA: MIT Press.

ROSCA, A. 2012. "Accounting for the constructional behavior of fetch, find, gather, and reach”. Revista Canaria de Estudios Ingleses 64, 161-176.

RUIZ DE MENDOZA, F. J. 2013. "Meaning construction, meaning interpretation and formal expression in the Lexical Constructional Model". Eds. E. DIEDRICHSEN and B. NOLAN. Linking Constructions into Functional Linguistics: The Role of Constructions in RRG Grammars. Amsterdam/Philadelphia: John Benjamins. 231-270.

RUIZ DE MENDOZA, F. J. and A. GALERA. 2014. Cognitive Modeling: A linguistic perspective. Amsterdam/Philadelphia: John Benjamins.

RUIZ DE MENDOZA, F. J. and R. MAIRAL. 2008. "Levels of description and constraining factors in meaning construction: An introduction to the Lexical Constructional Model”. Folia Linguistica 42, 2: 355-400.

2011. "Constraints on syntactic alternation: lexical-constructional subsumption in the Lexical-Constructional Model". Ed. P. GUERRERO. Morphosyntactic Alternations in English. Functional and Cognitive Perspectives. London, UK/Oakville, CT: Equinox. 62-82.

VAN DER LEEK, F. 1996. "Rigid Syntax and Flexible Meaning: The Case of the English Ditransitive”. Ed. A. E. GOLDBERG. Conceptual Structure, Discourse and Language. Stanford: CSLI Publications. 321-332.

WIERZBICKA, A. 1988. The semantics of grammar. Amsterdam: John Benjamins. 